\title{
A Method of Primary Cell Culture for Establishing Equine Long-Term Culture Cell Lines
}

\author{
Seiki WATANABE ${ }^{1 *}$, Youichirou ISHIKAWA ${ }^{1}$, Hiromi HARA ${ }^{1}$, Kei HANZAWA ${ }^{1}$ \\ and Harutaka MUKOYAMA ${ }^{2}$
}

${ }^{1}$ Laboratory of Animal Physiology, Tokyo University of Agriculture, 1-1-1 Sakuragaoka, Setagaya, Tokyo 156-8502, ${ }^{2}$ Equine Research Institute, Japan Racing Association, 321-4 Togami-machi, Utsunomiya, Tochigi 320-0856, Japan

\begin{abstract}
We investigated a method of culture for the establishment of equine long-term culture cell lines. The tissues tested were equine fetus tissues; right abdomen epithelium, the umbilical artery, the umbilical ring, the pulmonary artery, the renal cortex and the fetal placenta. To decide on a suitable primary culture method, we compared two methods of primary culture: tissue fragment culture and low-temperature trypsin cell-dispersal. On the other hand, to decide on a suitable culture medium, we compared 11 culture media: BME, MEM, D-MEM, IMDM and HFM (commercially completed culture media, available Human Foreskin Melanocyte). These were supplemented with $10 \%$ or $20 \%$ FCS when used as culture media. Moreover, HFM medium was used with no FCS, $10 \%$ and $20 \%$ FCS. Culture conditions were $37^{\circ} \mathrm{C}, 100 \%$ humidity, 5\% $\mathrm{CO}_{2}$ and 95\% air. We obtained the following results: 1) The tissue fragment culture method was suitable for preparing primary cell culture from fetal tissue. 2) High-nutrition culture media such as D-MEM and IMDM were suitable for the culture offetal tissues. 3) We established a cell line from cells of renal cortex, named "TEK-1".
\end{abstract}

Key words: cell, fetus, medium, cell culture

In order to isolate cells from tissue and to keep them for a long time to establish cell lines, Eagle and Piez pointed out that a suitable media is required for culture cells and that the culture environment should be made consistent [1]. In particular, this requires optimal culture conditions and operating technology to suit the animal species and different types of tissue cells, and many hours are needed until completion. For this reason, to date there have been hardly any cell lines suitable for longterm subculture of equine culture cells. There were a lot of human cell lines from various organs, but only equine cell lines from epithelium and primary culture cells such as the fetal kidney and spleen have been established $[6,7]$.

In the present study various organ tissues were extracted from an equine fetus with the aim of establishing equine cell lines, and efficient methods of isolating cells from these tissues were studied as well as methods for establishing cell lines and long-term culture of the isolated cells.

This article was submitted April 28, 1997 and was accepted September 22, 1997.

*corresponding author.
J. Equine Sci.

Vol. 8, No. 4

pp. $95-99,1997$

\section{Materials and Methods}

\section{Equine tissue samples}

Tissues were cut out from the left abdominal epithelium, umbilical artery, umbilical ring, pulmonary artery, renal cortex and fetal placenta of an equine fetus of 180 days gestation, and samples of each tissue were used for cell isolation.

\section{Equipment for culture}

The culture containers used in the experiment included 6-, and 24-well culture dishes (Corning: Cat. 430343, and 430246), and $50 \mathrm{ml}$ culture flasks (Iwaki Glass: Cat. 1100025).

To prevent adsorption of proteins and cells, pipettes and other glass implements were soaked for $2 \mathrm{hr}$ in a carbon tetrachloride solution including $0.2 \%$ dimethyl dicholorosilane and were baked for $30 \mathrm{~min}$ at $80^{\circ} \mathrm{C}$.

3. $\mathrm{CO}_{2}$ incubator

$\mathrm{A} \mathrm{CO}_{2}$ incubator (Forma Scientific Co.) was set at 
culture conditions of $37^{\circ} \mathrm{C}, 100 \%$ humidity, $5 \% \mathrm{CO}_{2}$ and $95 \%$ air.

\section{Experimental medium}

Basal Eagle's medium (BME; GIBCO, Cat. 21400041), Minimum essential medium (MEM; GIBCO, Cat. 22500-052), Dulbecco's modified Eagle's medium (DMEM; GIBCO, Cat. 12100-103) and Iscove's modified Dulbecco's medium (IMDM; GIBCO, Cat. 12200-085) were used as base culture media, with $100 \mathrm{mg}$ of streptomycin sulfate, and 100,000 units of penicillin G potassium per 1 litre of medium. These solutions were used after sterilizing through a $0.2 \mu \mathrm{m}$ filter. The commercially available Human Foreskin Melanocyte (HFM; Morinaga Seikagaku, Cat. 302008308), is a complete culture medium, MCDB153 as its base, that includes $10 \mu \mathrm{g} /$ liter phorbol-12-myrisate 13 -acetate (PMA), $10 \mu \mathrm{g} /$ liter cholera toxin, and $150 \mu \mathrm{g} /$ liter of Bovine pituitary extract [3].

The above base medium were supplemented with $10 \%$ and 20\% fetal calf serum (FCS; Toyobo, Lot. 97051001) and these were used as the culture media. Moreover, for the HFM, media with no FCS, $10 \%$, and $20 \%$ FCS were used.

\section{Trypsin-EDTA solution}

Two point five grams of crude trypsin (DIFCO, Cat. 0152-13-1, Lot. 56348JC) was dissolved in 1 liter of PBS (-) and the solution was adjusted to $\mathrm{pH}$ 8.0. One fifth of a gram of EDTA-2Na was added to this solution which, after agitated dissolution $\left(4^{\circ} \mathrm{C}, 24 \mathrm{hr}\right)$, was again adjusted to $\mathrm{pH}$ 7.2. After being filtered through a $0.2 \mu \mathrm{m}$ filter, the solution was aliquoted into tubes and stored in $-20^{\circ} \mathrm{C}$ until used.

\section{Cell counting}

A hemocytometer was used to count dispersed cells in media. To detect the viability of the cells a half volume of $0.4 \%$ tripan blue (in BBS) was added to the cells, and the cells that did not contain the dye were counted.

\section{Results}

\section{An efficient culture method for fetal tissue cells using the tissue fragment culture}

The various organ tissues derived from the fetus were cultivated by the tissue fragment culture method, a partly adjusted version of the standard culture method [6]. Namely, culture tissue portions were cut out on a sterilizer, and soaked for $1 \mathrm{hr}$ in a PBS (-) solution including $1 \mathrm{mg}$ /liter fungizon, $100 \mathrm{mg} /$ liter streptomycin sulfate, and 100,000 units/liter penicillin $\mathrm{G}$ potassium. Then, at the same time as removing surplus body fluid constituents from the extracted tissues, the tissues were quickly transferred to PBS (-) containing $1 / 10$ of the above mentioned antibiotics, and stored for $6-18 \mathrm{hr}$ at $4^{\circ} \mathrm{C}$.

These tissue portions were again cleaned 3 times in PBS (-), and after surrounding fat and fiber had been removed, were cut into about $2 \mathrm{~mm}$ squares with a pair of surgical knife blades. The resulting tissue fragments were placed in 6-well culture dishes at the rate of 3-4 pieces per well, and after they had been left to stand for a few minutes and the tissue fragments allowed to adhere to the surface of the dishes, the adjusted culture media were carefully added and the tissue fragments placed inside a $\mathrm{CO}_{2}$ incubator. After 10-15 days, cells grew from tissue fragments. These cells were dispersed by trypsin-EDTA solution at $37^{\circ} \mathrm{C}$ for $3-5$ min, diluted to a density of $1 \times 10^{5}$ living cells $/ \mathrm{ml}$ of culture medium in a $50 \mathrm{ml}$ culture flask, and placed in the incubator. Whenever cells grew and reached confluence, they were subcultured in the same way. The subculture results are shown in Table 1 and the shape shown in Figs. 1, 2.

For the epithelium and renal cortex tissues, both fibroblast-like and epithelial-like cells showed high growth in such high-nutrition culture media as D-MEM and IMDM but on subculture, epithelial cells could not endure many passages (see Table 1). On the other hand, renal cortex cells were showed signs of long term prolifelation on IMDM $+10 \%$ FCS. These cells were able to subculture 16 passages, but in the HFM and BME media, only a small increase in the number of cells was seen. But these were fibroblast-like cells, and perished after the first subculture.

In the umbilical artery tissues the proliferation rate was generally low. Little proliferating was seen in DMEM and IMDM, and the cells in both media could endure only one passage.

Cells from the pulmonary artery did not show fine prolifelation in any culture medium. Only in IMDM + $10 \%$ FCS culture medium was there a little prolifelation, but these cells perished after one passage.

In the umbilical ring, hardly any proliferation of cell tissue was seen, but in D-MEM and IMDM, some proliferation of fibroblast-like cells was seen. But the number of cell was small, and they had perished by the 15th day of culture.

In the fetal placenta tissues, good cell proliferation was seen in high-nutrition media at the beginning, but this prolifelation stopped after 7-12 days, and at last all perished. 
Table 1. Results of subculture: primary culture by the tissue fragment culture method

\begin{tabular}{|c|c|c|c|c|c|c|c|c|c|c|c|}
\hline \multirow{2}{*}{$\begin{array}{l}\text { Portion Medium } \\
\text { FCS density }(\%)\end{array}$} & \multicolumn{2}{|c|}{$\mathrm{BME}$} & \multicolumn{2}{|c|}{ MEM } & \multicolumn{2}{|c|}{ DMEM } & \multicolumn{2}{|c|}{ IMDM } & \multicolumn{3}{|c|}{ HFM } \\
\hline & 10 & 20 & 10 & 20 & 10 & 20 & 10 & 20 & 0 & 10 & 20 \\
\hline Epithelium & - & - & 1 & 1 & 1 & 1 & 1 & 4 & - & - & 1 \\
\hline Renal cortex & - & 1 & 1 & 1 & 3 & 6 & 16 & 8 & - & 1 & 1 \\
\hline Pulmonary artery & - & - & 1 & 1 & 1 & 6 & 1 & 6 & - & - & 1 \\
\hline Umbilical artery & - & - & - & - & - & 1 & 1 & 1 & - & - & - \\
\hline Umbilical ring & - & - & - & - & - & - & - & - & - & - & - \\
\hline Fetal placenta & - & - & - & - & - & - & 1 & 6 & - & - & - \\
\hline
\end{tabular}

*Numbers in the table are final subculture passages. "-" means no observed proliferative cells, or the cells proliferated but perished after subculture.

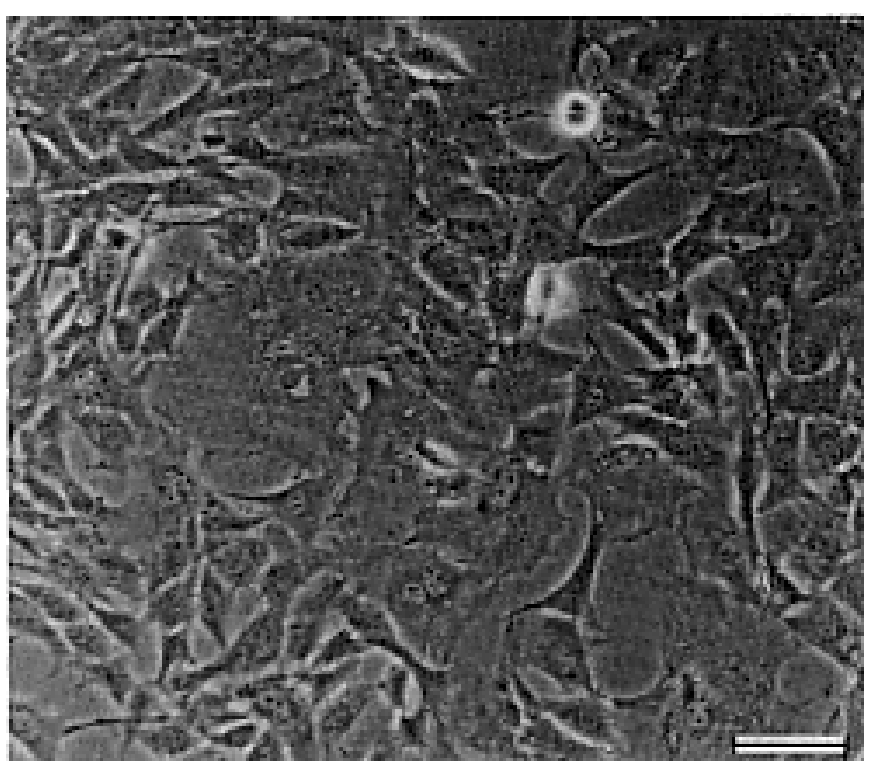

Fig. 1. Micrograph of Epithelial-like cells from renal cortex, in IMDM $+\mathrm{FCS} 10 \%(\mathrm{Bar}=100 \mu \mathrm{m})$.

\section{Cell dispersal method and culture method by means of low-} temperature trypsin cell dispersal

Portions of organ tissues extracted from the fetus were cut into about $2 \mathrm{~mm}$ squares by the same procedure as described above. The resulting tissue fragments were added to a trypsin-EDTA solution at the rate of 20-30 to $10 \mathrm{ml}$ and were left to stand at $4^{\circ} \mathrm{C}$ for $18 \mathrm{hr}$. Some of the tissue cells and tissue fragments that separated according to this trypsin method were replaced in fresh trypsin while being kept in a suspended state, after which they were heated at $37^{\circ} \mathrm{C}$ for $30 \mathrm{~min}$ in a $\mathrm{CO}_{2}$ incubator.

This culture medium including FCS was then subjected to neutralizing trypsin activation. The softened tissue fragments were disengaged by gently pipetting into suspended cells. The harvested cells were adjusted to a ratio of $1 \times 10^{5}$ living cell $/ \mathrm{ml}$ culture media (with the usual method, the final cell concentrations $3 \times 10^{5}$ to $1 \times$ $10^{6} \mathrm{cell} / \mathrm{ml}$ culture media [6]. But in this case, a small quantity of organ tissues, only gains a small number of cells), after which they were suspended in 24-well dishes and cultivated in a $\mathrm{CO}_{2}$ incubator. When these cells proliferated and reached confluence, they were subcultured in $50 \mathrm{ml}$ culture flasks, and were placed in the incubator. Whenever cells were confluent on the vessel, they were subcultured in the same way. The cultivation results are shown in Table 2 .

Generally proliferation of these cells was stopped after a short time. Epithelium and renal cortex cell were cultured in high-nutrition culture media as IMDM, and those from the pulmonary artery in MEM + 10\% FCS 


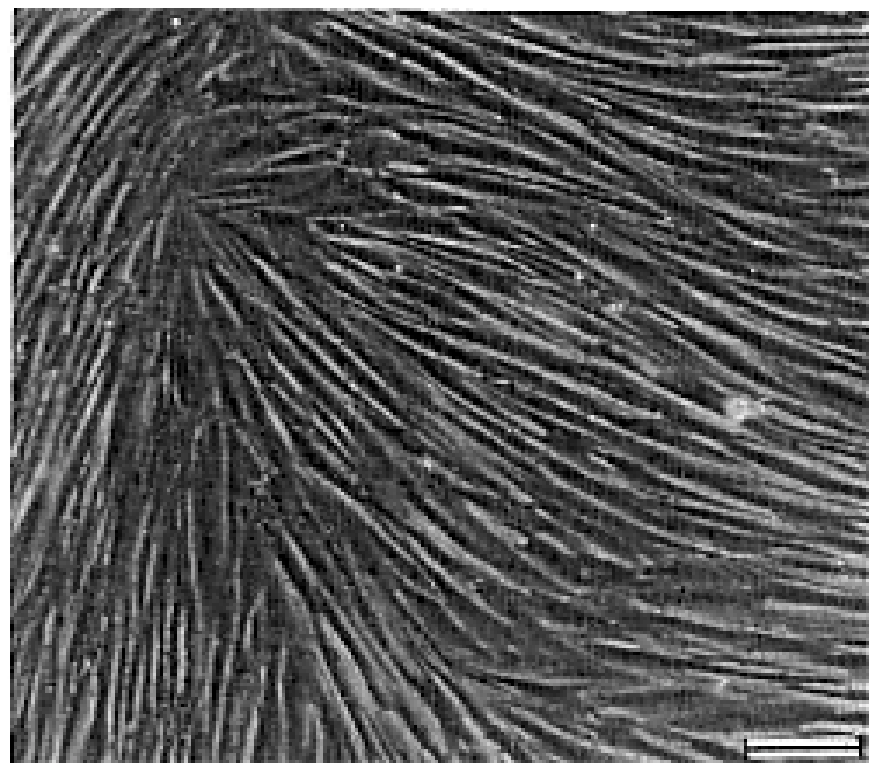

Fig. 2. Micrograph of Fibroblast-like cells from right abdomen epithelium, in DMEM + FCS 20\% (Bar=100 $\mu \mathrm{m})$.

Table 2. Results of subculture: primary culture by the low-temperature trypsine culture method

\begin{tabular}{|c|c|c|c|c|c|c|c|c|c|c|c|}
\hline \multirow{2}{*}{$\begin{array}{l}\text { Portion Medium } \\
\text { FCS density }(\%)\end{array}$} & \multicolumn{2}{|c|}{$\mathrm{BME}$} & \multicolumn{2}{|c|}{ MEM } & \multicolumn{2}{|c|}{ DMEM } & \multicolumn{2}{|c|}{ IMDM } & \multicolumn{3}{|c|}{ HFM } \\
\hline & 10 & 20 & 10 & 20 & 10 & 20 & 10 & 20 & 0 & 10 & 20 \\
\hline Epithelium & - & - & - & 1 & 1 & 1 & 4 & 6 & - & - & - \\
\hline Renal cortex & - & - & - & - & - & - & 4 & 4 & - & - & - \\
\hline Pulmonary artery & - & - & 1 & - & - & - & - & - & - & - & - \\
\hline Umbilical artery & - & - & - & - & - & - & - & - & - & - & - \\
\hline Umbilical ring & - & - & - & - & - & - & - & - & - & - & - \\
\hline Fetal placenta & - & - & - & - & - & - & - & - & - & - & - \\
\hline
\end{tabular}

*Numbers in the table are final subculture passages. "-” means no observed proliferative cells, or the cells proliferated but perished after subculture.

but there was little prolifelation, but many of the proliferated cells thus obtained either died in the serial subculture or stopped growing, both in the early stages. In other tissues either no proliferation at all was seen, or, even when proliferated was seen, they had either atrophied or died by the tenth day after the start of the culture.

\section{Discussion}

To achieve serial subculture of equine fetal cells, two methods were investigated in this study: the tissue fragment culture method in which tissues were cut out and cultured directly, and a method whereby the tissues were disrupted in trypsin-EDTA solution.

As a result, it seemed that the tissue fragment culture method, in which no particular processing is carried out, is suitable as a culture method for equine fetal cells. On the other hand, although the low-temperature trypsin celldispersal method (thought to involve relatively little cell damage [4]) was used as a method of preparing cells separation from organ tissue, the viability of the cells was low. In our former investigation, the cells were separated from equine fetus organs by the trypsin method, that is the tissues were directly dispersed in $37^{\circ} \mathrm{C}$ trypsin-EDTA for $30 \mathrm{~min}$, but these cells did not proliferate. From this result it may be deduced that the equine fetal cells are easily susceptible to damage by trypsin. On the other hand, Mccollum et al. established 
a trypsin cell-dispersal method for equine kidney cells [7] and many other cell lines were also isolated by the same method. The results in our experiment are different from many other reports in that there was susceptibility to damage to the cells caused by tripsin, so that this point requires further study.

Generally, fetal cells grow well in high-nutrition culture media [2]. This is thought to be because fetal cells are relatively undivided and have a high rate of nutritional demand because of their rapid proliferation. In this experiment, similarly, proliferation of cells from equine organs was favorable when cultivated in high-nutrition culture media. For this results it was considered that high-nutrition culture media were suited to the cultivation of equine fetal cells. But high-nutrition media (particularly D-MEM, containing large quantities of FCS) generally promote the growth of fibroblast cells, and considering that fibroblast cells suppress the growth of other cells, close attention should be paid to cell isolation and the selection of antibiotics when using these highnutrition media [5].

Although no favorable proliferation was seen in any of the cells with BME, this is thought to be because BME contains only basic nutrients.

As mentioned above, HFM is a culture medium that was developed to cultivate human foreskin melanocytes. The PMA and cholera toxin contained in this culture media have the function of suppressing the growth of fibroblast cells, and promoting the growth of melanocytes. When HFM was used in this experiment, proliferation was only seen in cells from epithelium, renal cortex and pulmonary artery tissues. This is thought to be because cells from these tissues, containing relatively few fibroblast cells, were able to proliferate due to the nature of the culture medium.

Comparing the viability of equine cells under the various FCS concentrations in the culture media, in most media it was better in FCS with a concentration of $20 \%$ than that with $10 \%$. This suggests that media with a larger serum content are effective for the primary culture of fetal cells. In other words, this is thought to be because fetal cells need more of the growth elements contained in serum, since these cells are undivided. But when comparing the results after serial subculture, those with a $20 \%$ FCS concentration divided off earlier, but those with $10 \%$ withstood longer term subculture. This point requires further study.

Finally we made a clonal culture cell line named "TEK1". This cell line was established from renal cortex cells cultured in IMDM $+10 \%$ FCS, the longest term proliferating cells that were cloned by dilution plating techniques, a cell in each well in a 96-well culture plate with $0.1 \mathrm{ml}$ of conditioning medium and cultured in a $\mathrm{CO}_{2}$ incubator.

The TEK-1 was derived from the 5 passaged renal cortex culture. This cell line was able to subculture 16 passages (one passage was 5-7 days), and the estimated cell population doubling level was about 50 PDL, but this requires more study.

\section{References}

1. Eagle, H. and Piez, K. 1962. The populationdependent requirement by cultured mammalian cells for metabolites which they can synthesize. $J$. Exp. Med. 116: 29-43.

2. Eagle, H. 1955. Nutrition needs of mammalin cells in tissue culture. Science 122: 501-504.

3. Eisinger, M. and Marko, O. 1981. Selective proliferation of nomal human melanocytes in vitro in the presence of phorbol ester and cholera toxin. Proc. Natl. Acad. Sci. USA. 79: 2018-2022.

4. Hayflick, L. and Moorhead, P.S. 1961. The serial cultivation of human diploid cell strains. Exp. Cell. Res. 25: 585-621.

5. Kan, M. and Yamane, I. 1982. In vitro proliferation lifespan of human diploid fibroblasts in serum-free BSA-containing medium. J. Cell. Physiol. 111: 155162.

6. Katuta, H.Takaoka, S. and Huh, N. 1980. Establishment of tissue culture cell strains from normal fetal human liver and kidney. Jpn. J. Exp. Med. 50: 329-337.

7. Mccollum, W.H., Doll, E.R., Wilson James, C. and Johnson Catherline B. 1961. Isolation and propagation of equine rhinopneumonitis virus in primary monolayer kidney cell cultures of domestic animals. Cornell. Vet. 52: 165-173. 